\title{
Inflammation of a small bowel leiomyoma mimicking acute appendicitis
}

\author{
P. A. HADLEY \\ M.B., B.S.
}

West Suffolk Hospital, Bury St Edmunds, Suffolk

\begin{abstract}
Summary
Small bowel leiomyoma has been well documented as a cause of unexplained gastrointestinal bleeding. It has not previously been associated with frank peritonitis as described here.

\section{Introduction}

Tumours of the small bowel are uncommon, the majority that do occur are malignant and symptomatic. Benign tumours, however, frequently cause no symptoms and may be discovered as an incidental finding at laparotomy or post-mortem. This case reports an unusual presentation of the commonest benign small bowel tumour, the leiomyoma.
\end{abstract}

\section{Case report}

A 61-year-old foreman presented with a history of
$36 \mathrm{hr}$ colicky low abdominal pain that had worsened to such a degree that he became bedridden before admission. He was nauseated and anorexic. The only previous hospital admission had been 4 years previously with a single episode of melaena, which had been ascribed to gastritis. Investigation at that time had been limited to upper gastro-intestinal endoscopy.

On examination he was flushed with a temperature of $37.8^{\circ} \mathrm{C}$. Abdominal examination revealed marked tenderness and guarding across the lower abdomen with rebound tenderness in the right iliac fossa. Haematological investigation revealed a haemoglobin of $10 \mathrm{~g} / \mathrm{dl}$, the blood films suggesting chronic irom deficiency. Plasma electrolytes were normal. Chesश and abdominal $\mathrm{X}$-rays were also normal. A provi sional diagnosis of acute appendicitis was made and an exploratory laparotomy performed through a grid-iron incision.

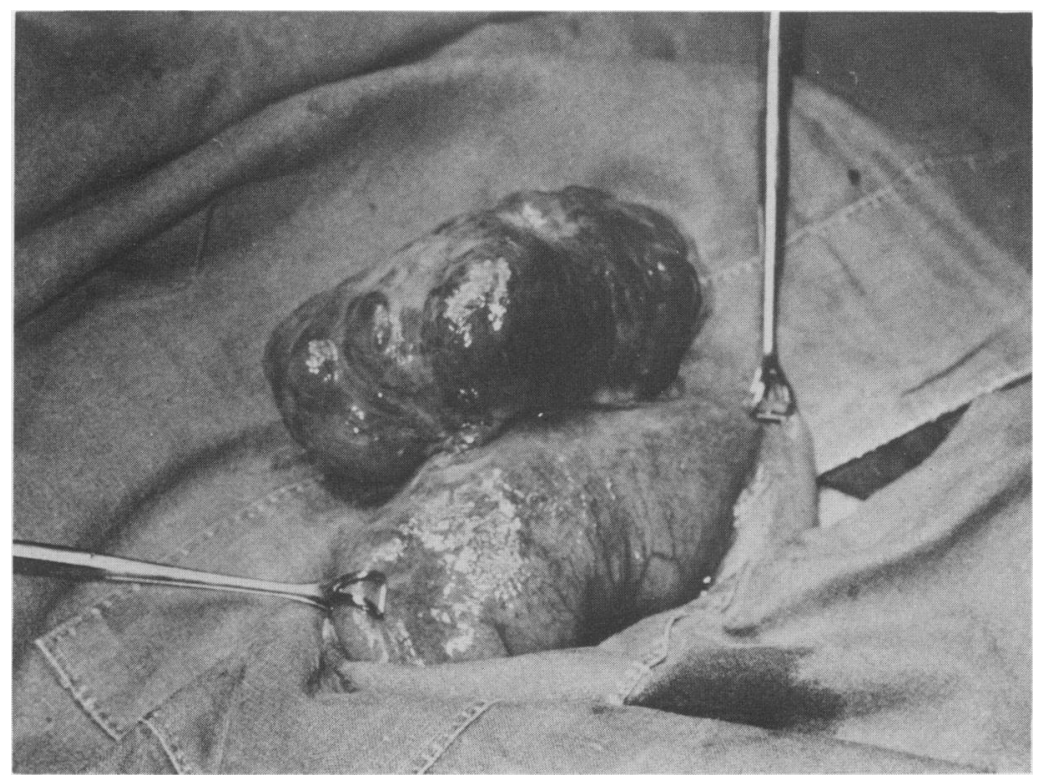

FIG. 1. Small bowel leiomyoma at operation. 


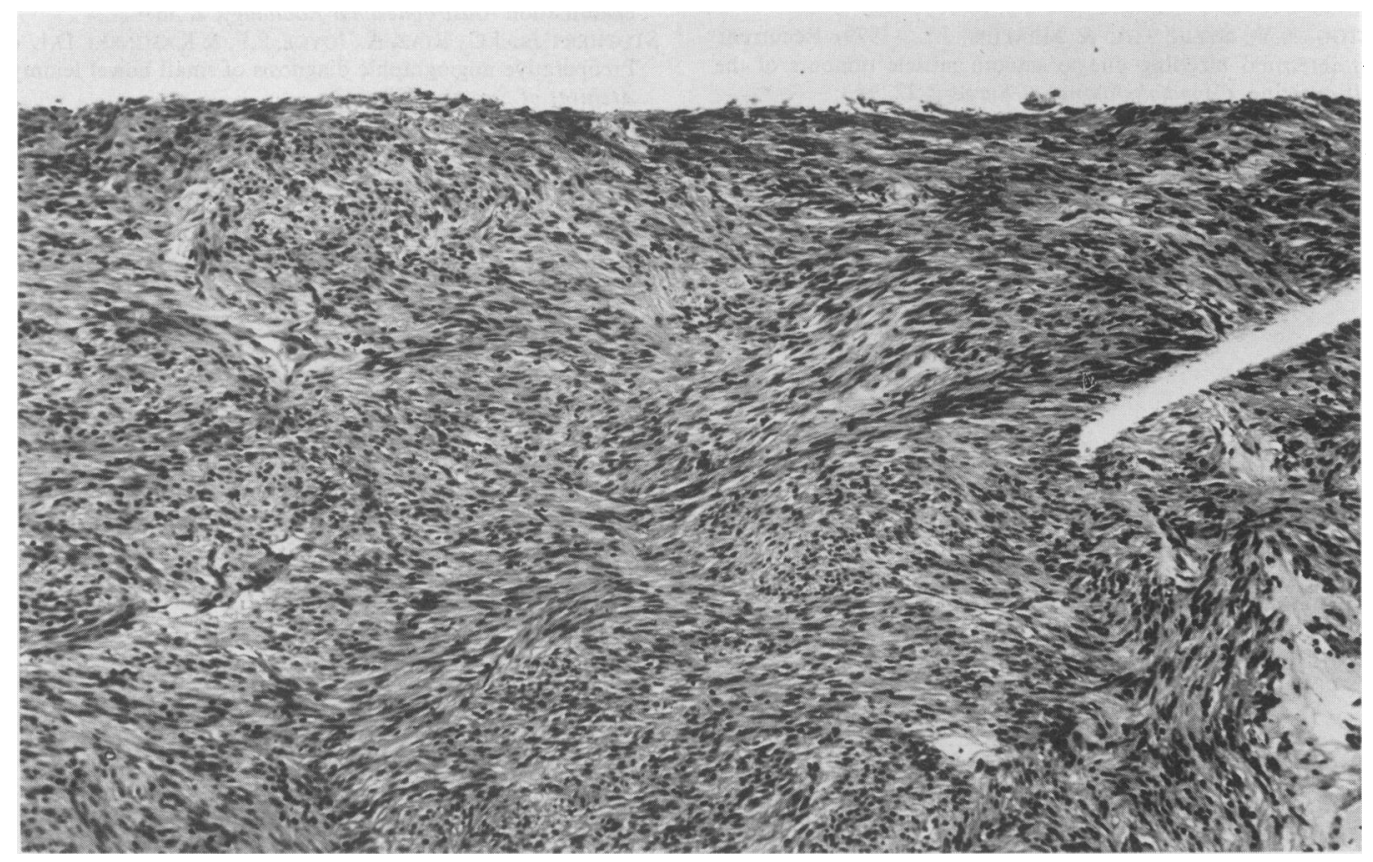

FIG. 2. Microscopic section of tumour $(\mathrm{HE}, \times 320)$. The tumour is contiguous with adjacent smooth muscle, with no capsule. The tumour cells vary in shape but are mainly fusiform and are arranged in palisade fashion.

At operation, free pus was found in the peritoneal cavity but the appendix was uninflammed. A swab was taken for microbiological examination and further exploration revealed a tumour arising from the anti-mesenteric border of the ileum, some 4 feet from the ileocaecal junction (Fig. 1).

There was no evidence of proximal obstruction, the surface of the tumour was necrotic with overlying pus which proved to be sterile but no definite perforation site could be found. A small bowel resection was carried out and the patient made an uneventful recovery. Histological examination of the resected specimen showed that the lesion was a benign leiomyoma arising subserosally in normal ileum (Fig. 2). A barium enema was obtained following recovery to exclude the possibility of a colonic cause for the finding of peritoneal pus, particularly in view of the fact that the tumour was not associated with perforation of the bowel wall.

\section{Comment}

The leiomyoma is a tumour of smooth muscle, common in the uterus but rare elsewhere. It is reported to form between $18 \%$ and $43 \%$ of all benign small bowel tumours (Wilson et al., 1975; Croom \& Newsome, 1975). Croom and Newsome described three different modes of presentation of small bowel leiomyomata-haemorrhage, obstruction and as an unexplained abdominal mass. Gastro-intestinal haemorrhage, which may be torrential or slow is probably the commonest presenting feature and many examples have been reported (Christou, Stein \& Mealum, 1979). The diagnosis may be indicated pre-operatively by the use of angiography (Stothert $e t$ al., 1978) or other radiological investigations (Miller and Lehman, 1978).

This case illustrates an unusual presentation of this uncommon tumour, with the presence of localized peritonitis and the development of sterile pus due to necrosis of the tumour surface. Although the likelihood of a leiomyoma causing symptoms which may be confused with acute appendicitis is remote, this does emphasize the importance of examining the small bowel at emergency appendicectomy if the appendix appears normal. The terminal ileum may be the site of Crohn's disease or yersineal infection and an inflammed Meckel's diverticulum has always to be excluded in cases of unexplained low abdominal pain.

\section{Acknowledgments}

I thank Dr F. Harris for examining the pathology specimens and Mrs Adam for typing the manuscript. 


\section{References}

Christou, N.V., Stein, L.A. \& Mealum, J.L. (1979) Recurrent gastrointestinal bleeding due to smooth muscle tumours of the small intestine. Canadian Journal of Surgery, 22, 95.

Croom, R.D. \& NEwSOME, J.F. (1975) Tumours of the small intestine. Annals of Surgery, 41, 160.

MILLER, R.E. \& LEHMAN, G. (1978) Gastrointestinal haemorrhage from ileal leiomyoma utility of the complete reflux small bowel examination. Gastrointestinal Radiology, 2, 367.

Stothert JR, J.C., RIAZ, A., JoYCE, P.F. \& KAMINSKI, D.L. (1978) Preoperative angiographic diagnosis of small bowel leiomyomas. Archives of Surgery, 113, 643.

Wilson, J.M., Melvin, D.B., Gray, G. \& Thorbjarwarson, B. (1975) Benign small bowel tumours. Annals of Surgery, 181, 247. 